\title{
Correction to: Increase in the prevalence of hypertension among adults exposed to the great Chinese famine during early life
}

Lingli Liu ${ }^{1,2,3 \dagger}$, Xianglong $X^{1,2,3 \dagger}$, Huan Zeng ${ }^{1,2,3}$, Yong Zhang ${ }^{1,2,3}$, Zumin Shi ${ }^{4}$, Fan Zhang ${ }^{1,2,3}$, Xianqing Cao ${ }^{1,2,3}$, Yao Jie Xie ${ }^{5}$, Cesar Reis ${ }^{6}$ and Yong Zhao ${ }^{1,2,3^{*}}$

\section{Correction}

The 'Conclusion' section in the Abstract was published incorrectly in the original publication of the article [1] exposure to the Chinese famine may be associated with an increased risk of hypertension in adulthood in women."

Line \#4 in Background on Page 1, "Hypertension causes a significant burden to the families and the society [1]."

The authors would like to correct the errors which have occurred in the 'Table' section, of the original publication as shown in the revised table.

Among male participants, we all use column percent in other variables, therefore, we should not use row percentage to describe "Fetal exposure" group, therefore, the authors would like to correct the error.

In 'Table 2' section, the number of vertical subheading "Childhood exposure $(n=455)$ " group and "Fetal and infant exposure $(n=299)$ " group was published incorrectly in the original publication of the article and are corrected with this erratum. The correct number should be "Childhood exposure $(n=299)$ " and "Fetal and infant exposure $(n=455)$ ". The underlined values in Table 1 and Table 2 have been corrected via this erratum. and is corrected with this erratum as below: "Fetal

Table 1 Characteristics of the study participants, Chongqing, China (\%)

\begin{tabular}{|c|c|c|c|}
\hline Variable & $\begin{array}{l}\text { Hypertension } \\
(n=150)\end{array}$ & $\begin{array}{l}\text { Non-Hypertension } \\
(n=1074)\end{array}$ & $p$-value \\
\hline $\begin{array}{l}\text { Timing of exposure to } \\
\text { famine }\end{array}$ & & & 0.0524 \\
\hline Childhood exposure & 32.00 & 23.37 & \\
\hline Fetal and infant exposure & 36.00 & 37.34 & \\
\hline Non-exposure & 32.00 & 39.29 & \\
\hline Gender & & & $<0.001^{* *}$ \\
\hline Male & 75.33 & 53.45 & \\
\hline Female & 24.67 & 46.55 & \\
\hline Male & & & 0.305 \\
\hline Childhood exposure & $\underline{29.20}$ & 23.34 & \\
\hline Fetal and infant exposure & 38.05 & 37.46 & \\
\hline Non-exposure & 32.74 & 39.20 & \\
\hline Female & & & 0.065 \\
\hline Childhood exposure & 29.73 & 37.20 & \\
\hline Fetal and infant exposure & 40.54 & 23.40 & \\
\hline Non-exposure & 29.73 & 39.40 & \\
\hline
\end{tabular}

Definition: 1$) *{ }^{*}$ Statistical difference exists $(p<0.001),{ }^{*}$ with statistical difference $(P<0.05)$

Table 2 Characteristics of the study participants, Chongqing, China

\begin{tabular}{lllll}
\hline Variable & $\begin{array}{l}\text { Childhood } \\
\text { exposure } \\
(n=299)\end{array}$ & $\begin{array}{l}\text { Fetal and } \\
\text { infant exposure } \\
(n=455)\end{array}$ & $\begin{array}{l}\text { Non-exposure } \\
(n=470)\end{array}$ & $p$-value \\
\hline Age (Mean/SD) & $49.69(0.79)$ & $47.28(0.45)$ & $43.44(0.62)$ & $<0.001^{* *}$
\end{tabular}

\footnotetext{
* Correspondence: zhaoyong@cqmu.edu.cn; zhaoyongzb@qq.com ${ }^{\dagger}$ Equal contributors

'School of Public Health and Management, Chongqing Medical University, Chongqing 400016, China

${ }^{2}$ Research Center for Medicine and Social Development, Chongqing Medical University, Chongqing 400016, China

Full list of author information is available at the end of the article
}

Definition: 1$)^{* *}$ Statistical difference exists $(p<0.001)$ 


\section{Author details}

${ }^{1}$ School of Public Health and Management, Chongqing Medical University,

Chongqing 400016, China. ${ }^{2}$ Research Center for Medicine and Social

Development, Chongqing Medical University, Chongqing 400016, China.

${ }^{3}$ The Innovation Center for Social Risk Governance in Health, Chongqing Medical University, Chongqing 400016, China. ${ }^{4}$ School of Medicine, Faculty of Health Sciences, The University of Adelaide, North Terrace, Adelaide, SA 5005, Australia. ${ }^{5}$ School of Nursing, The Hong Kong Polytechnic University, Hong Kong, Hong Kong, Special Administrative Region of China. ${ }^{6}$ Department of Preventive Medicine, Loma Linda University Medical Center, 24785 Stewart Street, Suite 204, Loma Linda, CA 92354, USA.

Received: 9 January 2018 Accepted: 15 February 2018

Published online: 15 March 2018

\section{Reference}

1. Liu, et al. Increase in the prevalence of hypertension among adults exposed to the great Chinese famine during early life. Environ Health Prev Med. 2017;22:64. https://doi.org/10.1186/s12199-017-0671-2. 